\title{
Vibration Control of Flexible Structures \\ Using Controllable ER Mounts : Experimental Investigation
}

\author{
제어 가능한 $\mathrm{ER}$ 마운트를 이용한 \\ 유연 구조물의 진동제어: 실험적 고찰
}

\author{
Seung-Bok Choi, Jung Woo Sohn and Young-Min Han \\ 최 승 복 $†$ 손 정 우*.한 영 민*
}

(Received February 9, 2009 ; Accepted March 30, 2009)

Key Words : ER Mount(ER 마운트), Vibration Control(진동제어), Flexible Structure(유연 구조물), Optimal Control(최적제어)

\begin{abstract}
This work presents experimental results on vibration control of flexible structures using the squeeze mode electrorheological(ER) mount. An appropriate size of the squeeze mode ER mount is devised and its field-dependent damping force characteristics are experimentally evaluated. The ER mount is then applied to two different flexible structures: beam structure and frame structure. An optimal controller associated with displacement and acceleration signals is designed to suppress the imposed vibration and experimentally realized using the microprocessor. Vibration control responses of the flexible structures such as acceleration are evaluated in time and frequency domains.
\end{abstract}

\section{요 약}

이 논문에서는 제어 가능한 $\mathrm{ER}$ 마운트를 이용한 유연 구조물의 진동제어 성능을 실험적으로 고찰하였 다. 압착 모드형 $\mathrm{ER}$ 마운트를 설계하고, 전기장 인가에 따른 댐핑력 특성을 실험적으로 평가하였다. 제작 된 $\mathrm{ER}$ 마운트를 빔과 프레임 형태의 유연 구조물에 적용하였고, 최적 제어기를 사용하여 시간 영역과 주 파수 영역에서 진동제어 성능을 평가하였다.

\section{Introduction}

Recently, the emergence of smart materials has accelerated successful development of high performance structural systems. So far, the smart materials include electrorheological(ER) fluids, magnetorheological fluids, piezoelectric materials

† 교신저자; 정회원, 인하대학교 기계공학부

E-mail : seungbok@inha.ac.kr

Tel : (032)860-7319, Fax : (032)860-1716

* 인하대학교 기계공학과 and shape memory alloys. These smart materials are employed primarily to vibration control of distributed parameter systems operating under variable service conditions. ER fluids undergo significant instantaneous reversible changes in material characteristics when subjected to electric potentials. The most significant change is associated with complex shear moduli of the material, and hence ER fluids can be usefully exploited in vibration-suppression situation where variable damping characteristics may be employed 
wide frequency ranges will be carried out by using smart materials.

\section{Acknowledgement}

This research was financially supported by the Ministry of Knowledge Economy(MKE) and Korea Industrial Technology Foundation(KOTEF) through the Human Resource Training Project for Strategic Technology. This financial support is gratefully acknowledged.

\section{References}

(1) Coulter, J. P. and Duclos, T. G., 1989, "Application of Electrorheological Materials in Vibration Control," Proceedings of the 2nd International Conference on ER Fluids, pp. 300 325.

(2) Choi, Y., Sprecher, A. F. and Conrad, H., 1992, "Response of Electrorheological Fluid-Filled Laminate Composites to Forced Vibration," Journal of Intelligent Material Systems and Structures. Vol. 3, No. 1, pp. 17 29.

(3) Choi, S. B., Choi, Y. K. and Cheong, C. C., 1996, "Active Vibration Control of Intelligent Composite Laminated Structures Incorporating an Electro-rheological Fluid," Journal of Intelligent Material Systems and Structures. Vol. 7, No. 4, pp. 411 419.

(4) Petek, N. K., Romstadt, D. J., Lizell, M. B. and Weyenberg, T. R., 1995, "Demonstration of an Automotive Semi-active Suspension Using Electrorheological Fluid," SAE Paper, 950586.

(5) Williams, E. W., Rigby, S. G., Sproston, J. L. and Stanway, R., 1993, "Electrorheological Fluid Applied to an Automotive Engine Mount," Journal of Non-newtonian Fluid Mechanics, Vol.47, pp. 221 238.

(6) Morishita, S. and Mitsui, J., 1992, “An Electronically Controlled Engine Mount Using Electro-rheological Fluid," SAE paper, 922290.

(7) Choi, S. B. and Choi, Y. T., 1999, "Sliding
Mode Control of Shear-mode Type ER Engine Mount," KSME International Journal. Vol. 13, No. 1, pp. $26 \sim 33$.

(8) Austin, S. A., 1993, "The Vibration Damping Effect of an Electrorheological Fluid," Journal of Vibration and Acoustics, Vol. 115, pp. 136 140.

(9) Wang, K. W., Kim, Y. S. and Shea, D. B., 1994, "Structural Vibration Control via Electrorheological-fluid-based Actuators with Adaptive Viscous and Frictional Damping," Journal of Sound and Vibration, Vol. 177, No. 2, pp. 227 237.

(10) Choi, S. B., 1996, "Vibration Control of a Flexible Structure Using ER Dampers," ASME Journal of Dynamic Systems, Measurement and Control, Vol. 121, No. 1, pp. 134 138.

(11) Hiemenz, G. J. and Wereley, N. M., 1999, "Seismic Response of Civil Structures Utilizing Semi-active MR and ER Bracing Systems," Journal of Intelligent Material Systems and Structures, Vol. 10, No. 8, pp. 646 651.

(12) Hong, S. R., Choi, S. B., Jung, W. J., Ham, I. B. and Kim, D. K., 2000, "Dynamic Characteristics of ER Mounts with Different Operation Modes," Transactions of the Korean Society for Noise and Vibration Engineering, Vol. 10, No. 5, pp. 819 829.

(13) Stanway, R., Sproston, J. L., Rigby, S. G. and Williams, E. W., 1994, "Modeling and Control of Electro-rheological Fluids in the Squeeze-flow Mode," Proceedings of the Second International Conference on Intelligent Materials, pp. 1176 1184.

(14) Stanway, R., Sproston, J. L. and Washed, A., 1999, "Adaptive Vibration Control Using the Electrorheological Squeeze-flow Damper," Proceedings of SPIE 2715, pp. 110 120.

(15) Choi, S. B., 2001, "High Damping Mechanism for Structural Systems Using ER Mounts," Technical Report for Korea Agency for Defense Development, pp. 7 16.

(16) Kirk, D. E., 1970, Optimal Control TheoryAn Introduction, Prentice-Hall, Englewood Cilffs, NJ, USA. 
to effectively control the response by tailoring the properties of the ER fluid.

The vibration control of flexible structures using the ER fluid can be achieved from two different methods. The first approach is to replace conventional viscoelastic materials by the ER fluid. So far, numerous researches have been undertaken in this way ${ }^{(1 \sim 3)}$. This method is very effective when the size of the flexible structure is small and the thickness of the structure is thin. The second approach to achieve vibration control of flexible structures is to utilize ER mount or ER damper. Originally, the idea of applying the ER mount to vibration control has been initiated in automotive engineering applications ${ }^{(4 \sim 7)}$. This idea can be easily exploited in structural vibration control $^{(8 \sim 11)}$. This method is effective for the vibration control of the large size of the flexible structures such as truss bridges and buildings in real world problems. When the ER mount(or damper) is used for vibration control, the operating mode of the mount can be classified by three different types: flow mode, shear mode, and squeeze mode. In the flow mode, it is assumed that two electrodes are fixed, and hence vibration control is achieved by controlling the flow motion between two fixed electrodes ${ }^{(4)}$. In the shear mode, it is usually assumed that one of two electrodes is free to translate or rotate relative to the other, and hence vibration control is achieved by controlling shear force between two electrodes ${ }^{(7,10 \sim 12)}$. Unlike the former two modes, in the squeeze mode the electrode gap is varied and the ER fluid is squeezed by a normal force. Using this mode, various mounts or dampers can be devised for vibration control ${ }^{(13,14)}$.

In this work, a new type of squeeze mode ER mount is proposed and applied to vibration control of flexible structures. An appropriate size of the squeeze mode ER mount is devised and its field-dependent damping force characteristics are experimentally evaluated. The ER mount is then applied to two different flexible structures: beam structure and frame structure. An optimal controller associated with displacement and acceleration signals is designed and experimentally realized using the microprocessor. Control responses of the flexible structures are evaluated in time and frequency domains.

\section{Controllable ER Mount}

The schematic configuration of the ER mount proposed in this work is shown in Fig. 1(a). The lower electrode is fixed to the base plate, while the upper electrode is to be moved up and down. Thus, the squeeze-mode motion of ER fluid occurs in the vertical direction. The coil spring is attached to support a static mass which is the mass of the flexible structures. Therefore, the proposed ER mount acts as a spring type passive mount in uncontrolled case. The total force of the proposed ER mount can be obtained by

$$
F(t)=k h(t)+c_{f}(t) \dot{h}(t)+f_{e r}(t)
$$

where,

$$
\begin{aligned}
c_{f}(t) & =\frac{3}{2} \frac{\pi \eta R^{4}}{\left(h_{o}+h(t)\right)^{3}} \\
f_{e r}(t) & =\frac{4}{3} \frac{\pi R^{3}}{h_{o}+h(t)} \tau_{y}(E) \operatorname{sgn}(\dot{h}(t))
\end{aligned}
$$

In the above, $k$ is the stiffness constant of the coil spring, $\eta$ is the viscosity of the ER fluid, $c_{f}(t)$ is the damping coefficient of the ER fluid in the absence of the electric field, $h(t)$ is the exciting displacement, $h_{o}$ is the initial gap between lower and upper electrodes, and $R$ is the radius of the circular electrode. $f_{e r}(t)$ is controllable damping force owing to the electric field $E$ of, and $\tau_{y}(E)$ is the field-dependent yield stress which is given by $\alpha E^{\beta}$. Here, $\alpha$ and $\beta$ are intrinsic values of the ER fluid to be experimentally determined. In this work, for the 


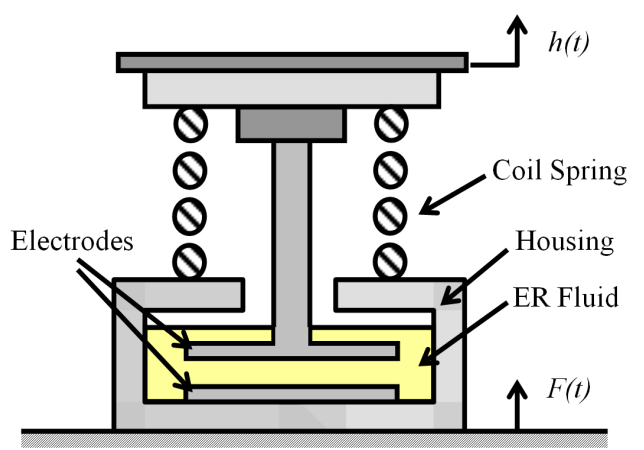

(a) Schematic diagram

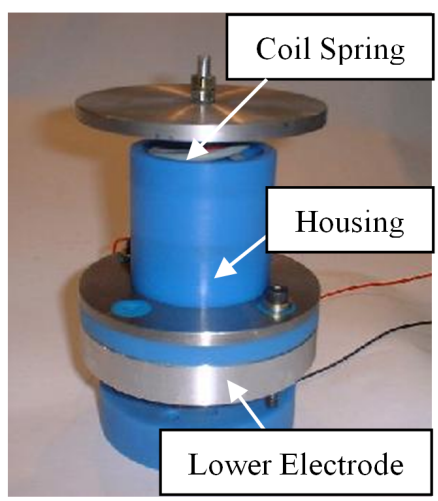

(b) Photograph

Fig. 1 The proposed ER mount

ER fluid, chemical starch and silicone oil whose viscosity is $30 \mathrm{cSt}$ are used for particles and base liquid, respectively. The intrinsic values of $\alpha$ and $\beta$ are experimentally obtained by 427 and 1.2 , respectively, at room temperature ${ }^{(15)}$.

By considering the mass of the beam and frame structures, an approximate size of the ER mount is manufactured as shown in Fig. 1(b). The radius of circular electrode is designed to be 15 $\mathrm{mm}$ and the initial gap is fixed by $3 \mathrm{~mm}$. The electrodes are made of duralumin, and the spring constant of the coil spring is $4 \mathrm{kN} / \mathrm{m}$. The height and outer diameter of the ER mount are $150 \mathrm{~mm}$ and $100 \mathrm{~mm}$, respectively. Fig. 2 presents time responses of the measured force of the ER mount. The excitation frequency is $75 \mathrm{~Hz}$, and the excitation amplitude is $\pm 40 \mu \mathrm{m}$. We clearly see the damping force is increased as the applied voltage increases. For instance, the force $0.6 \mathrm{~N}$ at
$1 \mathrm{kV}$ is increased up to $2.7 \mathrm{~N}$ by applying the voltage of $4 \mathrm{kV}$. We also tested the force at three different exciting frequencies and presented the results in Fig. 3. It is observed that the damping force can be electrically tuned at a certain exciting frequency. We also observe that slightly higher force is obtained at the higher excitation frequency with the same input voltage. This can be easily expected from the ER mount model given by Eq. (1).

In order to explicitly demonstrate the damping force controllability of the ER mount, an experimental test is undertaken. The desired damping force is imposed in the microprocessor, and a simple PID controller is designed so that actual damping force tracks to the desired one by applying an appropriate control voltage. So, the control electric field is determined by

$$
E(t)=k_{P} e(t)+k_{I}(t) \int e(t) d t+k_{D} \dot{e}(t)
$$

where,

$$
\begin{aligned}
e(t) & =F(t)_{\text {desiried }}-F(t)_{\text {actual }} \\
E(t) & =V(t) / h(t)
\end{aligned}
$$

In Eq. (3), $k_{P}, k_{I}$ and $k_{D}$ are proportional, integral and derivative control gains, respectively. Unlike the flow-mode or shear-mode ER mount, the electrode gap of the squeeze-mode ER mount varies with respect to the time. Therefore, the control electric field given by Eq. (3) should be converted to the actual voltage $V(t)$ by considering the time varing $h(t)$ in a real-time closed-loop manner. For the implementation, the control gains of $k_{P}, k_{I}$ and $k_{D}$ are chosen by $5.8,0.002$, and 0.01 , respectively. Fig. 4 presents the damping force controllability of the ER mount. The ER mount is excited by an electromagnetic shaker, and the produced damping force is measured by a load cell. The desired damping force trajectory which is expressed by $2 \sin (2 \pi \cdot 70 \cdot t) \mathrm{N}$ is well tracked by the actual one. 


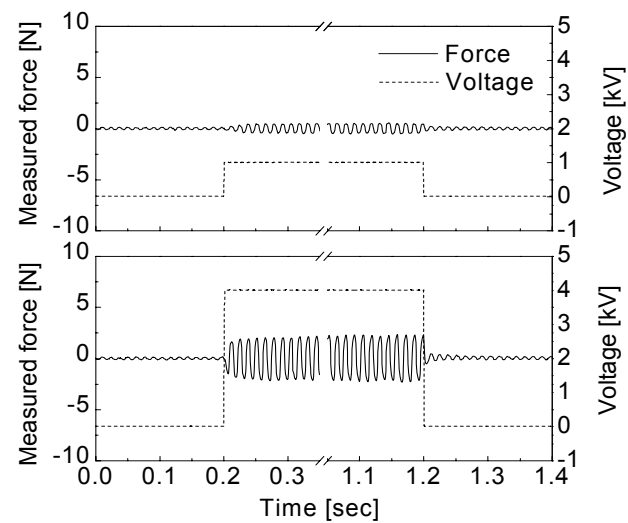

Fig. 2 Time response of the ER mount



(a) Excitation amplitude : $\pm 20 \mu \mathrm{m}$

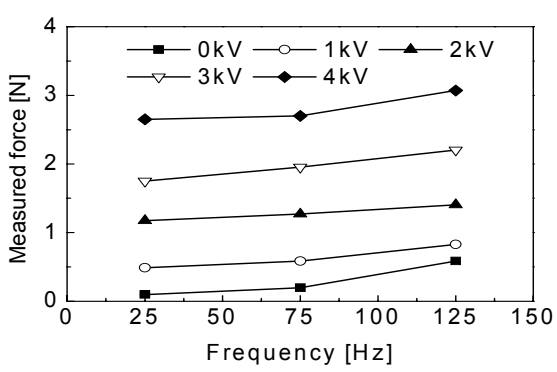

(b) Excitation amplitude : $\pm 40 \mu \mathrm{m}$

Fig. 3 Frequency response of the ER mount

This result directly indicates that the damping force of the squeeze mode ER mount can be effectively controlled by the electric field up to $70 \mathrm{~Hz}$. This control frequency of $70 \mathrm{~Hz}$ is the relatively high compared with the flow or shear mode ER mount ${ }^{(7)}$. It is noted that damping force controllability at $125 \mathrm{~Hz}$ has been also successfully verified. The high control performance of the squeeze mode ER mount is now applied to vibration control of the flexible structures.
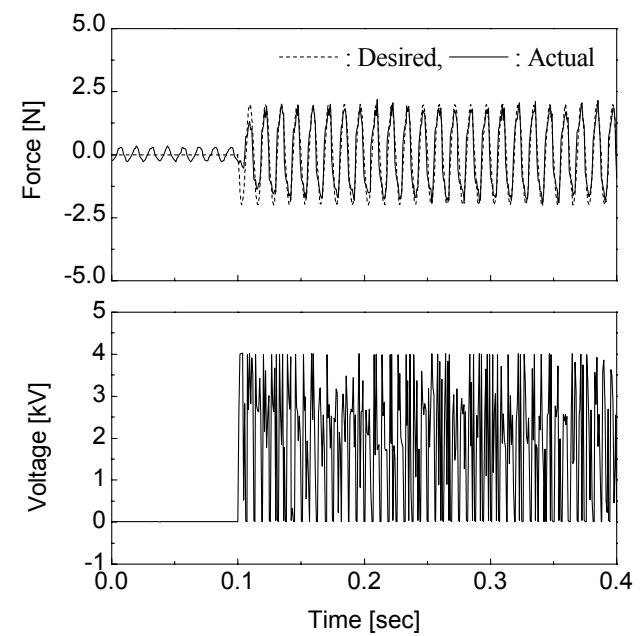

Fig. 4 Damping force controllability of the ER mount

\section{Application to Flexible Structures}

\subsection{Beam Structure}

In order to demonstrate vibration controllability of the proposed ER mount, two different flexible structures have been adopted in this experimental work. As a first application, a flexible steel beam (length $\times$ width $\times$ height $=1500 \mathrm{~mm} \times 60 \mathrm{~mm} \times 15$ $\mathrm{mm})$ was adopted. The natural frequency of the beam has been experimentally evaluated ; the first mode $=31.5 \mathrm{~Hz}$ and the second $\operatorname{mode}=83.8 \mathrm{~Hz}$. By considering these two modes as control modes an experimental apparatus was established as shown in Fig. 5. The beam is supported by two spring mounts positioned at each end and two ER mounts positioned at and $500 \mathrm{~mm}$ and $1000 \mathrm{~mm}$ from the left end.

The governing equation of motion of the proposed system is derived using Hamilton's principle, and its decoupled modal equation is given by

$$
\ddot{q}_{i}(t)+2 \varsigma_{i} \omega_{i} \dot{q}_{i}(t)+\omega_{i}^{2} q_{i}(t)=\frac{Q_{i}(t)}{I_{i}}+\frac{Q_{d i}(t)}{I_{i}}
$$

where 


$$
\begin{aligned}
& Q_{i}(t)=-\phi_{i}\left(l_{2}\right) F_{e r 2}(t)-\phi_{i}\left(l_{4}\right) F_{e r 4}(t) \\
& Q_{d i}(t)=\phi_{i}\left(l_{e x}\right) F_{e x}(t) \\
& I_{i}=\rho\left[\int_{0}^{l_{2}}\left(\phi_{i}^{(1)}(x)\right)^{2} d x+\int_{l_{2}}^{l_{4}}\left(\phi_{i}^{(2)}(x)\right)^{2} d x\right. \\
& \left.\quad+\int_{l_{4}}^{L}\left(\phi_{i}^{(3)}(x)\right)^{2} d x\right] \\
& y(x, t)=\sum_{i=1}^{\infty} \phi_{i}(x) q_{i}(t)
\end{aligned}
$$

In the above, $q_{i}(t)$ is the generalized modal coordinate. $\phi_{i}(t)$ is the mode shape. $\omega_{i}$ and $\varsigma_{i}$ are the natural frequency and damping ratio of the $i$ th vibration mode. $I_{i}$ is the generalized mass. $Q_{i}(t)$ is the generalized force concerned

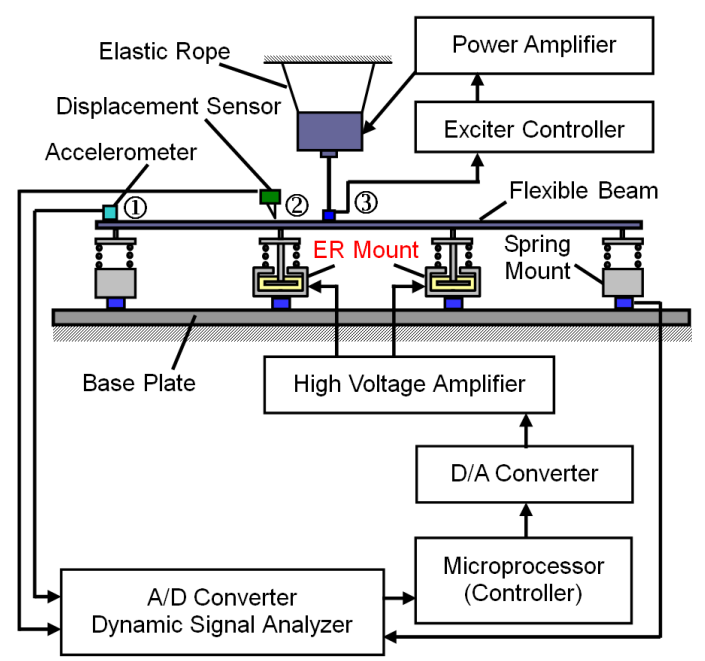

(a) Schematic diagram

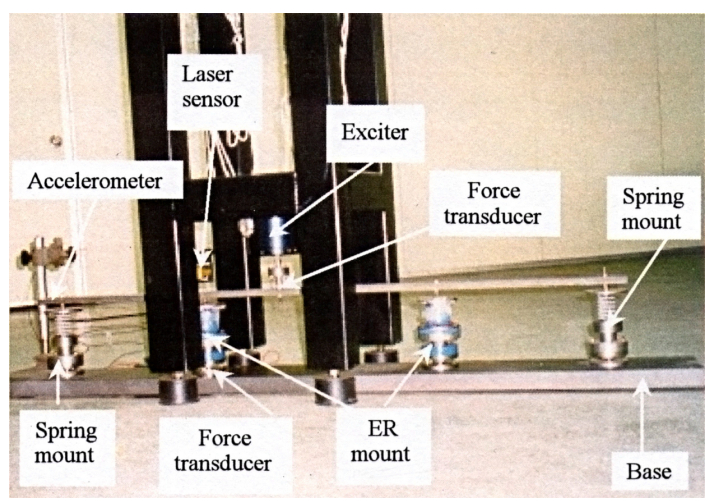

(b) Photograph

Fig. 5 Experimental apparatus for vibration control of the beam structure with the controllable damping force $\left(F_{e r}\right)$ acting on $l_{2}$ and $l_{4} \cdot Q_{e x i}(t)$ is the generalized force concerned with external force $\left(F_{e x}\right)$ acting on $l_{e x}$. Considering the boundary conditions, the first and second modes are chosen to be dominant for vibration characteristic. Thus, by defining the state variable $x(t)=\left[q_{1}(t) \dot{q}_{1}(t) q_{2}(t) \dot{q}_{2}(t)\right]^{T}$, the following system model is obtained.

$$
\begin{aligned}
\dot{x}(t) & =A x(t)+B u(t)+\Gamma d(t) \\
y(t) & =C x(t)
\end{aligned}
$$

In the above, $u(t)$ represents the control damping force and $d(t)$ is the external disturbance.

Among many potential controller candidates, an optimal controller to minimize the following performance measure is adopted.

$$
J=\int_{0}^{\infty}\left\{x(t)^{T} Q x(t)+u(t)^{T} R u(t)\right\} d t
$$

where $Q$ and $R$ weighting matrices. The controller is then obtained from the Riccati equation as follows ${ }^{(16)}$.

$$
u(t)=-R^{-1} B^{T} K x(t)
$$

where $K$ is the feedback gain.

In the experiment of vibration control, the beam is to be externally excited by the electromagnetic exciter, and displacement sensor and accelerometer are used to catch the vibration signals. The signals are fed back to the microprocessor through analog/digital(A/D) converter. And depending on the signal information control voltage is determined by the optimal controller. The control voltage is then applied to the ER mount through high voltage amplifiers, which have a gain of 1000. In the controller implementation, the maximum voltage is limited by $4 \mathrm{kV}$ for safety. The sampling frequency to realize the controller was chosen by $2 \mathrm{kHz}$, and the software was written by Borland $\mathrm{C}++$. The marks denoted by (1), (2) and (3) on the beam 
represents the measured points. In the controller realization, the following feedback gains are used : $\quad k_{21}=-0.1798, \quad k_{22}=-139.46, \quad k_{23}=96.9, \quad k_{24}=$ $-0.11, \quad k_{41}=-0.1165, k_{42}=98.85, \quad k_{43}=139.83, k_{44}$ -0.1796 .

Figure 6 presents time responses of the vibration signals when the beam structure is excited by the first mode natural frequency $(31.5$ $\mathrm{Hz}$ ). It is clearly seen that both displacement at the position 2 and acceleration at the position 1 are substantially reduced by activating the proposed ER mount. The peak value of displacement of the position 1 is reduced about $95 \%$ from $\pm 300 \mathrm{~mm}$ to $\pm 4 \mathrm{~mm}$ and acceleration at the position 2 are reduced and $90 \%$ from \pm 39 $\mathrm{m} / \mathrm{s}^{2}$ to $\pm 5 \mathrm{~m} / \mathrm{s}^{2}$. It is remarked that uncontrolled response is obtained in the absence of the control voltage. Acceleration levels at the positions 1, 2 and 3 are measured in the frequency domain and presented in Fig. 7. We clearly observe that accelerations at the two resonance frequencies are

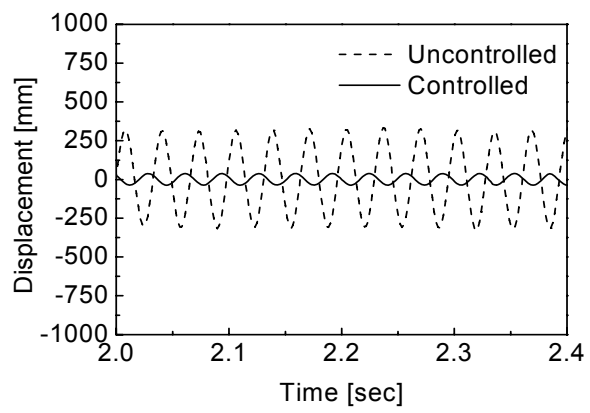

(a) Displacement at position 2



(b) Acceleration at position 1

Fig. 6 Vibration response of the beam structure in time domain remarkably attenuated by employing the control voltage to the ER mount. Because the position 3 sensor lies at the midpoint and node of the beam structure, the second mode response cannot be measured. In this work, a quality value ( $\mathrm{Q}$ value) is evaluated via half power method to quantify the vibration reduction. By activating the ER mounts, the $\mathrm{Q}$ values are reduced up to $89.1 \%$ and $66.7 \%$ in the first and second modes, respectively. It is noted that the ER mount acts as a spring type passive mount in uncontrolled case. Therefore, the demonstrated comparison between controlled and uncontrolled cases corresponds to the comparison between all passive mounts support and the ER mounts + passive mounts support.

\subsection{Frame Structure}

As a second application example, a frame structure consisting of the L-shaped cross-sectional steel components was adopted. The frame
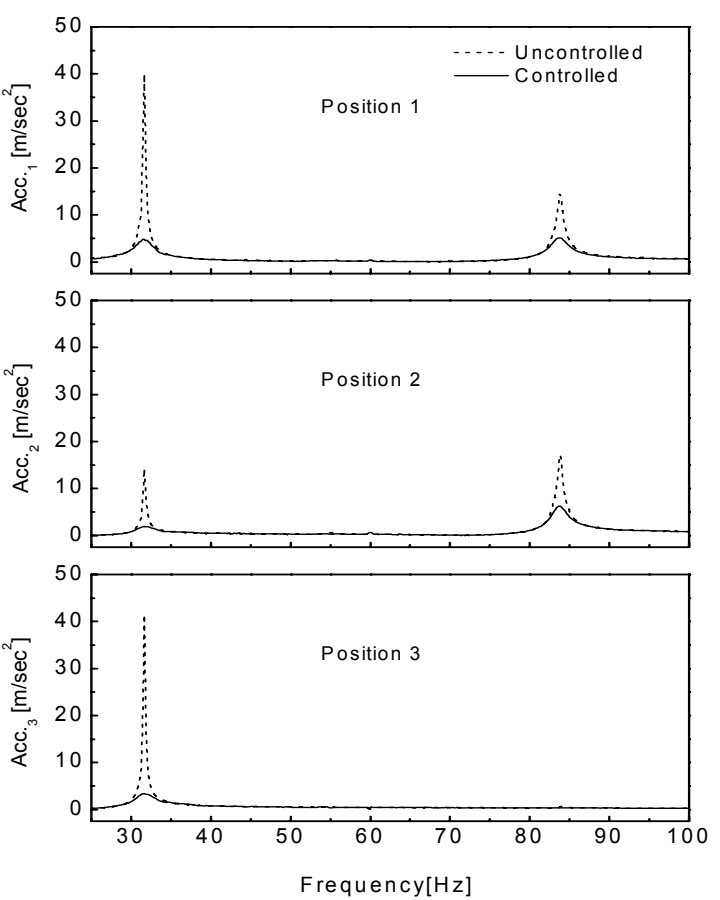

Fig. 7 Acceleration of the beam structure in frequency domain 
structure has the length of $1200 \mathrm{~mm}$ and the width of $800 \mathrm{~mm}$ and supported by four spring mounts and two ER mounts as shown in Fig. 8. Four spring mounts are fixed at four corners and two ER mounts are attached at the middle of the structure. The position of the ER mounts was determined by observing experimentally measured mode shapes of the frame structure. Fig. 9 presents the measured mode shapes of the first two bending modes of the frame structure. It is clearly seen that the first two bending modes can be effectively controlled by installing the ER mounts at the middle of the structure. In addition, it is observed that there is no significant difference in mode shapes between with and without voltage. After identifying modal parameters, the governing equation of motion is established and the same optimal controller for the beam structure is designed to attenuate unwanted vibration.

In the experiment of vibration control, the flexible frame is excited by the electromagnetic shaker, and excitation force level and frequency are regulated by exciter control. The displacement and acceleration of the structure are measured using the laser sensor and accelerometer, respectively. These signals are fed back to the microprocessor via A/D (analog to digital) converter. Depending on the signal information appropriate control voltages are determined by means of the optimal controller. The control voltages are applied to the ER mounts via $\mathrm{D} / \mathrm{A}$ (digital to analog) converter and a high voltage amplifier which has a gain of 1000 . The sampling frequency in the controller implementation was chosen by $2 \mathrm{kHz}$. In the controller realization, the following feedback gains are used : $\quad k_{21}=-0.0271, \quad k_{22}=22.351, \quad k_{23}=0.133, \quad k_{24}=$ $-0.116, \quad k_{51}=0.115, \quad k_{52}=0.0035, \quad k_{53}=2.956$, $k_{54}=0.0208$.

Figure 10 presents the time responses of displacement(at the position 1) of the frame

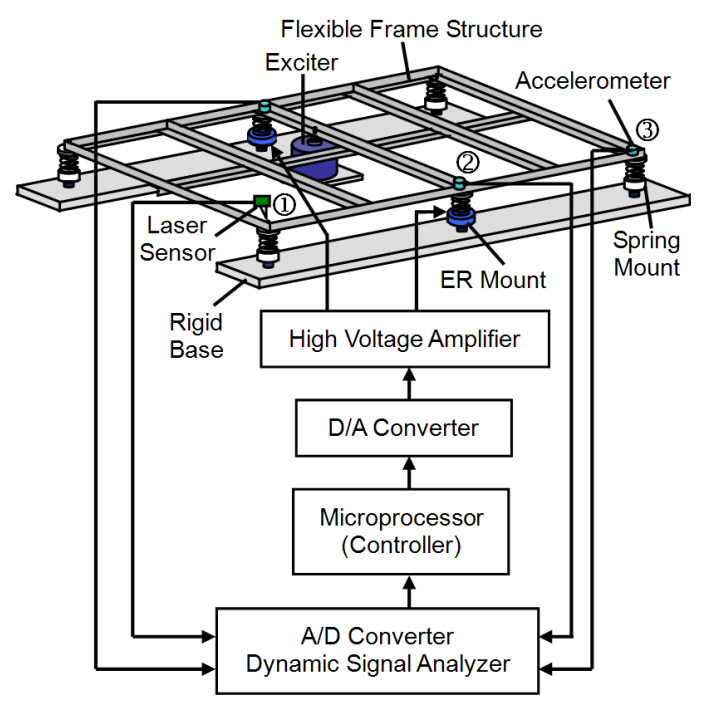

(a) Schematic diagram

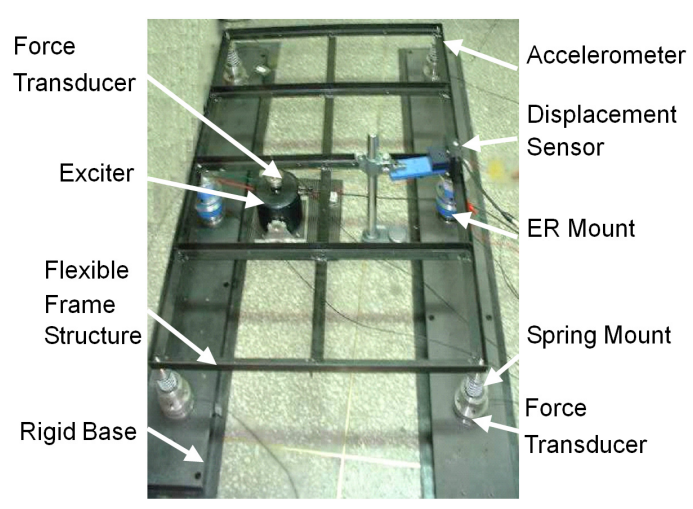

(b) Photograph

Fig. 8 Experimental apparatus for vibration control of the frame structure

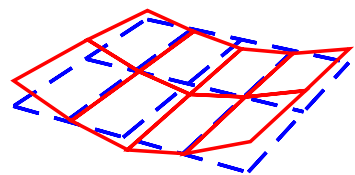

$0 \mathrm{kV}(59.25 \mathrm{~Hz})$

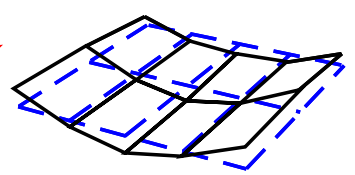

$1 \mathrm{kV}(59.27 \mathrm{~Hz})$ (a) 1 st bending mode



$0 \mathrm{kV}(66.50 \mathrm{~Hz})$

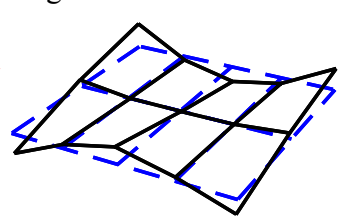

$1 \mathrm{kV}(66.58 \mathrm{~Hz})$ (b) 1 st torsional mode

Fig. 9 Measured mode shapes of the frame structure 


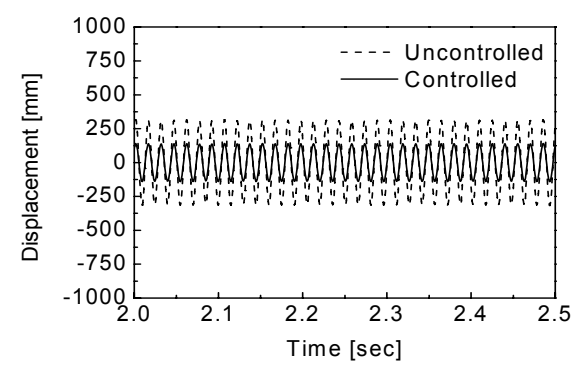

(a) Displacement at position 1

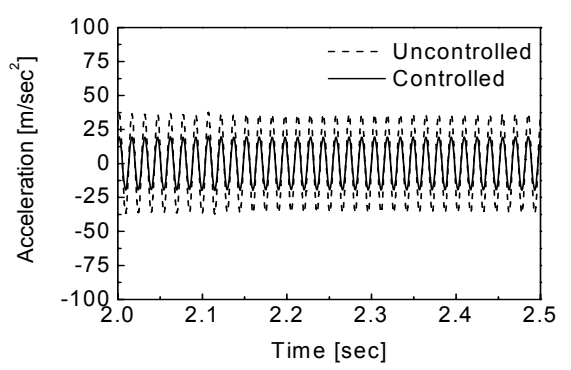

(b) Acceleration at position 2

Fig. 10 Vibration responses of the frame structure in time domain
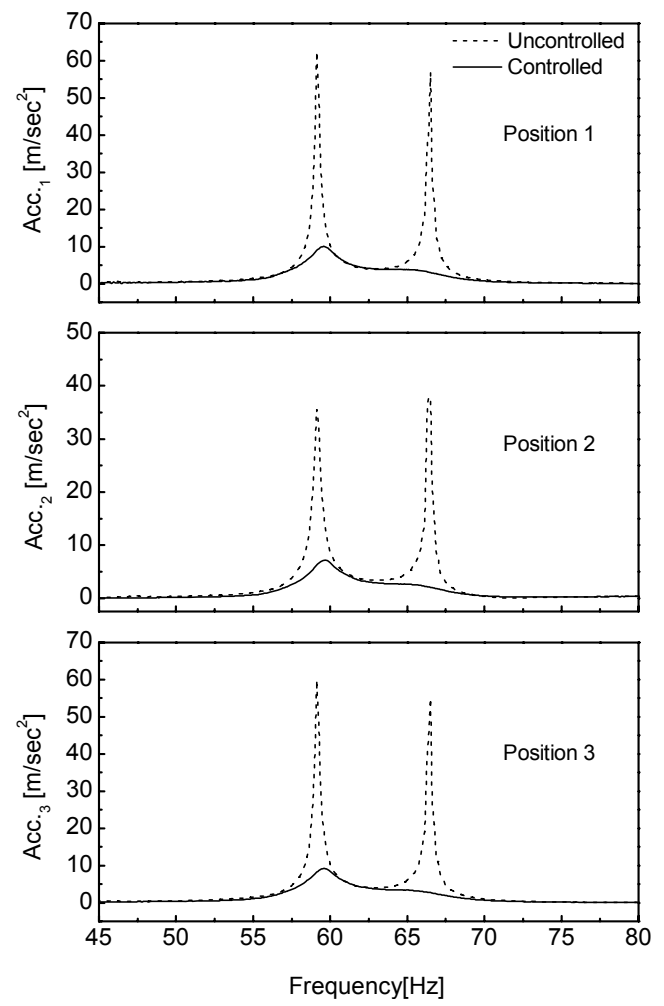

Fig. 11 Acceleration of the frame structure in frequency domain structure and acceleration(at the position 2) of the frame structure. The exciting frequency is 59.25 $\mathrm{Hz}$ and the exciting force amplitude is $2 \mathrm{~N}$. It is clearly seen that vibration levels of the frame structure are substantially reduced by activating the proposed ER mounts. The peak value of displacement of the position 1 is reduced about $55 \%$ from $\pm 300 \mathrm{~mm}$ to $\pm 130 \mathrm{~mm}$ and acceleration at the position 2 are reduced and $45 \%$ from \pm 36 $\mathrm{m} / \mathrm{s}^{2}$ to $\pm 19 \mathrm{~m} / \mathrm{s}^{2}$. It is remarked that uncontrolled response is obtained in the absence of the voltage. Accelerations of the frame structure at the positions 1, 2 and 3 are measured in the frequency domain and presented in Fig. 11. We clearly see that the acceleration of the frame structure at the resonance frequencies is remarkably reduced by employing the control voltages to the ER mounts. The reduced percentages of $\mathrm{Q}$ values are $84.7 \%$ and $99.7 \%$ in the first and second modes, respectively.

\section{Concluding Remarks}

In this work, an experimental investigation on the vibration control of flexible structures was undertaken by adopting controllable ER mounts. After manufacturing the squeeze mode ER mount, the field-dependent damping forces have been experimentally evaluated. The ER mounts were then integrated with the beam and frame structures to attenuate vibrations. Both displacement and acceleration signals were measured and chosen as feedback signals, and control voltages were determined through the optimal control logic. It has been demonstrated through experimental implementation that vibrations of the flexible beam and frame structures can be reduced about $89.1 \%$ and $84.7 \%$, respectively, in terms of the quality value(Q) value at the first resonant frequencies by activating the proposed ER mount. As a next step of this work, researches on active vibration control of the flexible structures in the 